tions of this, his favourite, field of research, and did his best to build up really adequate series upon which future systematists could work. It will require the labour of two or three generations of systematists to exhaust the possibilities of the material now available. It is to be hoped that the Tring Museum will be carried on as a living institution and that enough neighbouring land can be acquired to admit of future extension.

\section{Protection of Aborigines}

RECENT correspondence in the Press has shown that there is a considerable body of public opinion which is still far from satisfied with the treatment accorded the races of backward civilization under British jurisdiction, notwithstanding the undoubted improvement in conditions and a more sympathetic attitude towards them to be observed in recent years. With a view to the possibility of further improvement, it has been decided by persons and organizations interested in the problem to hold a public meeting for the discussion of the question of their preservation. The meeting will be held by permission of the Council of the Royal Empire Society in the Assembly Hall of that body on April 28 at 3.45 p.m. The chair will be taken by Lord Moyne, who will speak on "Natives in the Solomon Islands". Other speakers will be Dr. W. van Waterschoot van der Gracht, president of the Pygmy Sub-Committee of the Nederlandsche Commissie voor Internationaale Natuurbescherming, on "The Preservation of Backward Primitive Races"; Dr. John R. Baker on "The Natives of the New Hebrides"; and Dr. Julian Huxley, who will deal generally with the preservation of primitive cultures. Tickets of admission, which is free, may be obtained from the Secretary, Aborigines Protection Society, Denison House, 296 Vauxhall Road, S.W.1.

\section{Indian Cultural Studies}

NotwithstandING the assurance that the Indian collections of the Victoria and Albert Museum, South Kensington, were not to be dispersed and that space would continue to be provided for them in the galleries of that Museum, which followed Mr. de la Valette's lecture before the Indian Section of the Royal Society of Arts (see NATURE, December 25, p. 1108, and January 29, p. 177), the critics of the methods of the ethnographical sections of our national collections are still of the opinion that less than justice is done to requirements for the study of the cultural history of India, compared with what might be attempted with the resources at command. A joint committee accordingly has been formed, consisting of representatives of the five bodies more intimately concerned in the study of India and her peoples. These are the Royal Society of Arts (Indian Section), the India Society, the Royal Asiatic Society, the East India Association and the School of Oriental Studies. Although the joint committee has as yet, it is understood, arrived at no decision as to its precise aims and methods of procedure, in principle the general purpose is to secure provision which in scope and display, dignity and standing, will be worthy of so great a dependency as India, with its tradition of advanced civilization stretching back thousands of years, and as the place of origin of at least one of the religious systems of the world's history. The traditions of the Victoria and Albert Museum, though it included 'industry' in its original purview, are not such as to foster a treatment of Indian culture in which technology and the humbler arts of life have no less claim, if not indeed a stronger claim, to treatment than fine art. But while the Indian collections continue to be merely a department of a larger unit, they must be subordinated to the purpose of the whole. The joint committee has been criticized, notably by the writer of a letter in The Times of March 23, as academic; but surely if its purpose is rightly understood, it is precisely the academic spirit which it aims to avoid. What could be more closely in touch with modern India than a comprehensive museum of Indian culture, which should cover both past and present?

\section{University of Birmingham}

AT the last meeting of the Council of the University of Birmingham, the following resolution was passed : "The Council has considered the recommendation of the Finance and General Purposes Committee with regard to the pressing needs of the Department of Physics, involving a capital outlay of about $£ 60,000$. It unanimously recognizes the urgency of the requirements, but, owing to the present state of University finance, regrets that it is not possible at present to put this work in hand. It is, however, most desirable in the interests both of teaching and research that there should be no delay, and the Council would be most grateful for any financial help from outside to enable the University to meet these requirements." This is a sequel to a report on the needs of the Physics Department made to the Council by Prof. M. L. Oliphant, who points out that the equipment and general facilities of the Department are totally inadequate for present needs. The time has come to review the temporary expedient adopted twenty years ago of having a considerable portion of the Department in old army huts.

THE scheme for extension of the Physics Depart. ment proposed by Prof. Oliphant includes an additional block which would consist of a large central research hall suitable for high-voltage work, flanked by a number of research rooms, a machine room, workshop, dark rooms and a basement room for high-energy X-ray work. The general idea is that the buildings themselves should be simple and less costly than those of the remainder of the University, and the design should be elastic to be capable of readjustment with the changing needs of physical research. The present building could then be used entirely for teaching work and accommodation of staff. Unfortunately, it appears that architectural considerations require that the frontage to the great court should be of the massive and costly type exhibited in the rest of the University building as a 